\title{
Establishment of a rat ovarian peritoneal metastasis model to study pressurized intraperitoneal aerosol chemotherapy (PIPAC)
}

Leen Van de Sande ${ }^{1,2}$ (D) Wouter Willaert ${ }^{1,2}$, Sarah Cosyns ${ }^{1,2}$, Kaat De Clercq ${ }^{2,3}$, Molood Shariati ${ }^{4}$, Katrien Remaut ${ }^{2,4}$ and Wim Ceelen ${ }^{1,2,5^{*}}$

\begin{abstract}
Background: pressurized intraperitoneal aerosol chemotherapy (PIPAC), with or without electrostatic precipitation (ePIPAC), was recently introduced in the treatment of peritoneal metastases (PM) from ovarian cancer (OC). Preliminary clinical data are promising, but several methodological issues as well the anticancer efficacy of PIPAC remain unaddressed. Here, we propose a rat ePIPAC model that allows to study these issues in a clinically relevant, reproducible, and high throughput model.

Methods: laparoscopy and PIPAC were established in healthy Wistar rats. Aerosol properties were measured using laser diffraction spectrometry based granulometric analyses. Electrostatic precipitation was accomplished using a commercially available generator (Ultravision ${ }^{\mathrm{TM}}{ }^{\mathrm{M}}$. A xenograft model of ovarian PM was created in athymic rats using intraperitoneal (IP) injection of SKOV-3 luciferase positive cells. Tumor growth was monitored weekly by in vivo bioluminescence imaging.

Results: PIPAC and electrostatic precipitation were well tolerated using a capnoperitoneum of $8 \mathrm{mmHg}$. All rats survived the (e)PIPAC procedure and no gas or aerosol leakage was observed over the entire procedure. With an injection pressure of 20 bar, granulometry showed a mean droplet diameter $(D(v, 0.5))$ of $47 \mu \mathrm{m}$ with a flow rate of $0.5 \mathrm{~mL} / \mathrm{s}$, and a significantly lower diameter $(30 \mu \mathrm{m})$ when a flow rate of $0.8 \mathrm{~mL} / \mathrm{s}$ was used. Experiments using IP injection of SKOV-3 luciferase positive cells showed that after IP injection of $20 \times 10^{6}$ cells, miliary PM was observed in all animals. PIPAC was feasible and well supported in these tumor bearing animals.

Conclusions: we propose a reproducible and efficient rodent model to study PIPAC and PPIPAC in OC xenografts with widespread PM. This model allows to characterize and optimize pharmacokinetic and biophysical parameters, and to evaluate the anti-cancer efficacy of (e)PIPAC treatment.
\end{abstract}

Keywords: PIPAC, ePIPAC, Ovarian cancer, Peritoneal metastases, Laparoscopic surgery, Intraperitoneal drug delivery, Rat xenograft

\footnotetext{
* Correspondence: Wim.Ceelen@UGent.be

${ }^{1}$ Laboratory of Experimental Surgery, Department of Human Structure and Repair, Ghent University, Ghent, Belgium

${ }^{2}$ Cancer Research Institute Ghent (CRIG), Ghent University, Ghent, Belgium

Full list of author information is available at the end of the article
}

(c) The Author(s). 2019 Open Access This article is distributed under the terms of the Creative Commons Attribution 4.0 International License (http://creativecommons.org/licenses/by/4.0/), which permits unrestricted use, distribution, and reproduction in any medium, provided you give appropriate credit to the original author(s) and the source, provide a link to the Creative Commons license, and indicate if changes were made. The Creative Commons Public Domain Dedication waiver (http://creativecommons.org/publicdomain/zero/1.0/) applies to the data made available in this article, unless otherwise stated. 


\section{Background}

Selected patients with peritoneal metastases (PM) benefit from cytoreductive surgery (CRS) combined with hyperthermic intraperitoneal chemoperfusion (HIPEC) $[1,2]$. However, many patients present with irresectable disease, which has a dismal prognosis. Survival in patients with irresectable PM from colon cancer is 15 months, from gastric cancer 4 months, and from pancreatic cancer only 6 weeks [3-5]. Systemic chemotherapy is relatively inefficient in PM due to poor vascularity of peritoneal tumor nodules [6, 7]. Pressurized intraperitoneal aerosol chemotherapy (PIPAC) is a novel locoregional treatment modality which involves intraperitoneal (IP) delivery of chemotherapy as an aerosol during laparoscopic surgery $[7,8]$. Chemotherapy is aerosolized in the abdominal cavity using a high-pressure injector and a nebulizer (Capnopen ${ }^{\circ}$ ). This method allows aerosolized chemotherapy to interact directly with tumor tissue. In addition, the elevated intra-abdominal pressure may enhance tumor tissue drug penetration [9].

Despite the significant potential of PIPAC and the preliminary clinical data already available, many technological and anti-cancer properties of the technique remain to be elucidated. In recent clinical practice, PIPAC was combined with electrostatic aerosol precipitation using the Ultravision ${ }^{\mathrm{mw}}$ system [10]. This device, originally developed to clear smoke from the laparoscopic operating field by an electrostatic force, uses a stainless-steel microfilament brush (Ionwand ${ }^{\mathrm{m}}$ ) which is inserted into the abdominal cavity [11]. A high DC voltage (7.5-9.5 $\mathrm{kV}, \leq 10 \mu \mathrm{A})$ is applied to the Ionwand, resulting in a corona discharge and a stream of negatively charged ions, which attach to suspended particles. These now negatively charged aerosol particles are attracted to the positive charge of the return electrode. In theory, the combination of electrostatic precipitation with PIPAC, termed ePIPAC, can result in increased tissue uptake of the aerosolized chemotherapy. However, this theoretical advantage remains to be confirmed in well-designed preclinical as well as clinical studies [12].

Several in vitro experimental PIPAC models have been described. The cytotoxic efficacy of PIPAC was investigated in vitro using proliferation assays of human colon cancer cells [13]. An in vitro model consisting of aerosol generation in a plastic box that contains human peritoneum with PM was used to study tissue penetration of doxorubicin, as well as the effect of treatment parameters such as nebulizer position, pressure, and drug dose $[14,15]$. Schnelle et al. developed an interesting ex vivo model that consists of an inverted bovine urinary bladder, resulting in a serosa-lined cavity that can be used to study PIPAC [16]. Solass and coworkers demonstrated the technical proof of principle of PIPAC in a pig model [17]. However, the pig model is cumbersome, labour intensive, and expensive, and does not allow to study anticancer properties in xenografted or syngeneic PM. Here, we report the first small animal model of PIPAC and ePIPAC that allows to study several important endpoints such as tissue penetration and anti-cancer efficacy in PM of human origin.

\section{Methods}

\section{Granulometric analyses}

Volume-weighted particle size distribution (PSD) of aerosol droplets was performed in triplicate by laser diffraction (Mastersizer S long bench, Malvern Instruments, Worcestershire, United Kingdom). The size of aerosol droplets was measured in an open laser beam (water vs. air, refractive index of 1.33 and 1.00 respectively) using a $300 \mathrm{~F}$ lens $(0.5-900 \mu \mathrm{m})$ over a time horizon of 10 to $20 \mathrm{~s}$ after initiation of injection. Saline was nebulized using a commercially available nebulizer (Capnopen ${ }^{\circ}$, Capnomed, Zimmern, Germany) and a high-pressure injector (Injektron ${ }^{\mathrm{Tm}} 82 \mathrm{M}$, Medtron, Saarbrücken, Germany). The outlet of the nebulizer was perpendicularly secured at a distance of $35 \mathrm{~mm}$ to the beam and $100 \mathrm{~mm}$ to the lens. The laser diffraction measurements were performed as soon as the high-pressure injector achieved the desired injection conditions, i.e. 10 $\mathrm{s}$ after initiating the injection. Results are expressed by median of volume distribution, $\mathrm{D}(\mathrm{v}, 0.5)$, i.e. the size at which $50 \mathrm{vol} \%$ of the droplets were either finer or coarser than the predicted value, with standard deviation.

\section{Ex vivo simulation of PIPAC}

A $12 \mathrm{~mm}$ balloon trocar (Kii, advanced fixation sleeve, Applied Medical, Amersfoort, The Netherlands) was inserted in a closed $100 \mathrm{~mL}$ ethylene vinyl acetate (EVA) bag. $\mathrm{CO}_{2}$ was insufflated to establish a constant pressure of $8 \mathrm{mmHg}$. Twenty $\mathrm{mL}$ of undiluted royal blue ink (Pelikan nv, Groot-Bijgaarden, Belgium) was nebulized into the EVA bag with a flow rate of $0.8 \mathrm{~mL} / \mathrm{s}$ and a maximal upstream injection pressure of $20 \mathrm{bar}$. The nebulizer was fixed either perpendicularly to the surface of the EVA bag, or in a slightly tilted position.

\section{Animals}

Adult Wistar Hannover rats $(n=3$ preliminary experiment; $n=6$ in vivo experiment; Envigo, Horst, The Netherlands) and adult athymic nude rats $(n=9$; Envigo, Horst, The Netherlands) were allowed to acclimatize to the surroundings for at least three days and were kept in standard housing conditions with water and food ad libitum and a $12 \mathrm{~h}$ light/dark cycle. After the experiments, all rats were euthanized with a lethal injection of T-61 $(0.3 \mathrm{~mL} / \mathrm{kg}, \mathrm{IV})$ into the tail vein. The experiments were approved by the Animal Ethical Committee of the 
Faculty of Medicine of Ghent University, Belgium (ECD 17-50 and ECD 18-30).

\section{Surgical methods \\ Experimental protocol of PIPAC in rats}

The experimental procedure of PIPAC in the rat was based on clinical treatment protocols [18, 19]. Adult Wistar Hannover rats $(n=6)$ were anesthetized with sevoflurane ( $8 \mathrm{vol} \%$ induction, $4 \mathrm{vol} \%$ maintenance). Animals were placed in a class II laminar flow hood (Airstream, Esco Global, Barnsley, United Kingdom) in a supine position and fixed at all four extremities. The abdomen was shaved and disinfected. Next, a $5 \mathrm{~mm}$ and a $12 \mathrm{~mm}$ balloon trocar were inserted and a constant capnoperitoneum pressure of $8 \mathrm{mmHg}$ was established (Olympus UHI-3 insufflator, Olympus Surgical Technologies Europe, Hamburg, Germany). Each trocar was secured by a tripod. The nebulizer was then connected to the high-pressure injector through a high-pressure line and inserted into the abdominal cavity using the 12 $\mathrm{mm}$ trocar. Afterwards, a $5 \mathrm{~mm}$ laparoscope was introduced into the abdominal cavity using the $5 \mathrm{~mm}$ trocar. The tightness of the abdomen was documented via absence of $\mathrm{CO}_{2}$ flow. Next, the high-pressure injector was activated. Injection parameters were set at a flow rate of $0.8 \mathrm{~mL} / \mathrm{s}$ and a maximal upstream injection pressure of $20 \mathrm{bar}$. When used with the nebulizer, the high-pressure injector needs up to $10 \mathrm{~s}$ to achieve the desired conditions (flow rate and injection pressure). Therefore, the high-pressure injector was set to inject $8 \mathrm{~mL}$ of air during these first $10 \mathrm{~s}$, before nebulizing $20 \mathrm{~mL}$ of saline at the desired conditions. The capnoperitoneum pressure of $8 \mathrm{mmHg}$ was maintained for $30 \mathrm{~min}$. Thereafter, the aerosol was evacuated through a closed aerosol waste system containing a 99.999\% ULPA-carbon filter. Finally, trocars were removed, and the laparoscopic procedure was terminated. The abdomen was closed with a two-layered running suture (Vicryl Plus 4-0 Ethicon, Johnson \& Johnson international, Sint-StevensWoluwe, Belgium) and analgesia was administered (Ketoprofen, $5 \mathrm{mg} / \mathrm{kg}$, SC).

\section{Electrostatic precipitation}

In three adult Wistar Hannover rats, the use of Ultravi$\operatorname{sion}^{\text {Tu }}$ technology (Alesi Surgical, Cardiff, United Kingdom) was added to the PIPAC-setup. The system was activated at the start of aerosol generation and the electric current was maintained for $30 \mathrm{~min}$. The Ultravision ${ }^{\mathrm{mm}}$ system integrates the following components: a generator unit (voltage $7500-9500 \mathrm{~V}$, current $\leq 10 \mu \mathrm{A}$ ), an active cable terminating in an atraumatic stainless-steel brush electrode (Ionwand) that is responsible for the electrostatic charging of aerosol particles, and a return electrode with a solid return plate. To obtain a closed electrical circuit, the solid return plate was fixed under a metal plate. During the ePIPAC procedure, the rat was positioned on this metal plate (Fig. 1).

\section{Rat ovarian PM model}

SKOV-3 Luc IP2 cells, a human ovarian carcinoma cell line created by double in vivo selection of SKOV-3 Luc cells, were used to create a rat xenograft model [20]. The cells (kindly donated by Olivier De Wever, Laboratory of Experimental Cancer Research, Ghent University) were cultured at $37^{\circ} \mathrm{C}$ in a $10 \% \mathrm{CO}_{2}$ containing atmosphere in McCoy's 5A medium (ThermoFisher Scientific Bvba, Merelbeke, Belgium) supplemented with $10 \%$ fetal bovine serum, penicillin and streptomycin (ThermoFisher Scientific Bvba, Merelbeke, Belgium).

Athymic nude rats $(n=9)$ were injected IP with $5 \times$ $10^{6}(n=3), 10 \times 10^{6}(\mathrm{n}=3)$ or $20 \times 10^{6}(\mathrm{n}=3)$ SKOV-3 Luc IP2 cells in a volume of $5 \mathrm{~mL}$ saline. The rats underwent a daily subcutaneous injection of cyclosporine (3 mg) starting three days prior to, and until four weeks

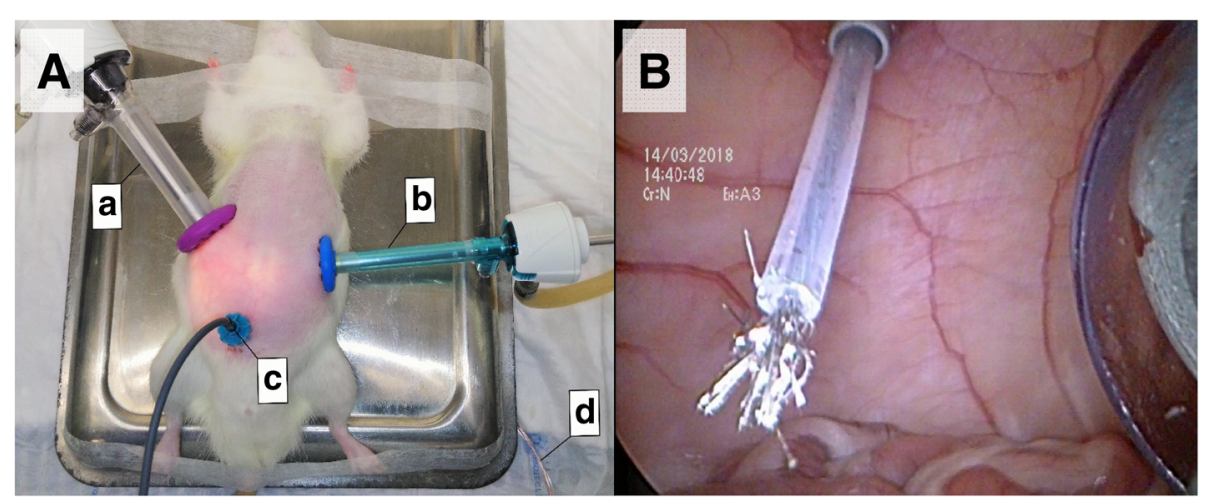

Fig. 1 A ePIPAC setup in a healthy Wistar Hannover rat. $12 \mathrm{~mm}$ balloon trocar with nebulizer and closed aerosol waste system (a), $5 \mathrm{~mm}$ balloon trocar with laparoscope and $\mathrm{CO}_{2}$ insufflator (b), lonwand (c), electrical conductor between return electrode (underneath metal plate) and generator unit (d). B Intra-abdominal view of the lonwand in a healthy Wistar Hannover rat 
after tumor cell inoculation to ensure tumor growth. Tumor growth was monitored by weekly in vivo bioluminescent imaging (BLI) (IVIS Lumina II, PerkinElmer, Zaventem, Belgium). Imaging was performed 12 min after IP injection of D-luciferin $(120 \mathrm{mg} / \mathrm{kg}$; PerkinElmer, Zaventem, Belgium). The exposure time was one second and the binning (resolution setting) was set to medium.

After four weeks, PIPAC and ePIPAC with saline were performed according to the abovementioned experimental procedures. The rats were euthanized $24 \mathrm{~h}$ after (e)PIPAC with a lethal injection of T-61 $(0.3 \mathrm{~mL} / \mathrm{kg}$, IV) into the tail vein. Peritoneal tumors were excised and embedded in paraffin for standard hematoxylin and eosin (H\&E) staining.

\section{Statistical analysis}

Differences between $\mathrm{D}(\mathrm{v}, 0.5)$ values were compared using the non-parametric Mann-Whitney $U$ test since data were not normally distributed. A $p$-value of $\leq 0.05$ was considered to indicate statistical significance.

\section{Results}

Influence of physical parameters on aerosol formation

A maximal upstream injection pressure of $20 \mathrm{bar}$ and a fixed flow rate of $0.5 \mathrm{~mL} / \mathrm{s}$ were associated with a $\mathrm{D}(\mathrm{v}, 0.5)$ of $47 \pm 2 \mu \mathrm{m}$ (Fig. 2a). Decreasing the maximal upstream injection pressure to $10 \mathrm{bar}$, resulted in an increased $\mathrm{D}(\mathrm{v}, 0.5)$ of $51 \pm 1 \mu \mathrm{m} \quad(p=0.127)$. However, when the maximal upstream injection pressure was further decreased to $5 \mathrm{bar}, \mathrm{D}(\mathrm{v}, 0.5)$ remained $51 \pm 2 \mu \mathrm{m}(p=0.127)$.

Analysis of different flow rates $(0.5$ and $0.8 \mathrm{~mL} / \mathrm{s})$ at a fixed maximal upstream injection pressure of $20 \mathrm{bar}$, showed a strong impact on the volume-weighted PSD curves (Fig. 2b). Applying a flow rate of $0.5 \mathrm{~mL} / \mathrm{s}, \mathrm{D}(\mathrm{v}, 0.5)$ was $47 \pm 2 \mu \mathrm{m}$. Increasing the flow rate to $0.8 \mathrm{~mL} / \mathrm{s} \mathrm{re}$ sulted in a decreased $\mathrm{D}(\mathrm{v}, 0.5)$ of $30 \pm 3 \mu \mathrm{m}(p=0.05)$.

Bimodal volume-weighted PSD curves were observed when nebulization of saline was done in a closed environment using a plastic box (Fig. 2c). Aerosol formation in patient-like conditions, i.e. nebulization of $200 \mathrm{~mL}$ saline with a maximal upstream injection pressure of 20 bar and a flow rate of $0.5 \mathrm{~mL} / \mathrm{s}$ in a plastic box of $5 \mathrm{~L}$, showed a $\mathrm{D}(\mathrm{v}, 0.5)$ of $35 \pm 1 \mu \mathrm{m}$. After nebulization with rat-like conditions, i.e. nebulization of $20 \mathrm{~mL}$ with a maximal upstream injection pressure of $20 \mathrm{bar}$ and a flow rate of $0.8 \mathrm{~mL} / \mathrm{s}$ in a plastic box of $100 \mathrm{~mL}$, a $\mathrm{D}(\mathrm{v}, 0.5)$ of $25 \pm$ $3 \mu \mathrm{m}(p=0.05)$ was detected.

Adequacy of stain distribution throughout the entire EVA bag was clearly superior with a slightly tilted nebulizer position (Fig. 3). Specifically, the top of the EVA bag was stained when the nebulizer was secured in a tilted position, while this was not the case when it was placed perpendicularly.

\section{Experimental PIPAC procedure}

Once the ideal injection parameters for (e)PIPAC were determined, PIPAC with saline was tested in healthy Wistar Hannover rats $(n=3)$. The feasibility of repeated PIPAC applications was successfully tested in these preliminary experiments. The three rats underwent three consecutive PIPAC procedures with an interval of four weeks. The rats tolerated multiple PIPAC applications very well and were in good health after the third PIPAC application. Thereafter, PIPAC $(\mathrm{n}=3)$ and ePIPAC $(\mathrm{n}=$ 3) was performed in healthy adult Wistar Hannover rats. Procedures were executed as planned in both groups. The nebulizer enabled rapid and effective nebulization of saline in the abdominal cavity without extracorporeal leakage of aerosolized droplets over the entire setup. All rats survived the procedures.

\section{Rat ovarian PM model}

In vivo BLI of tumor-bearing rats is illustrated in Fig. 4. In the first $\left(5 \times 10^{6} \mathrm{SKOV}-3\right.$ Luc IP2 cells $)$ and second group $\left(10 \times 10^{6}\right.$ SKOV-3 Luc IP2 cells), no diffuse PM was observed. After four weeks, two rats had only one tumor nodule and in the other specimens no tumor growth occurred. However, in the third group $\left(20 \times 10^{6}\right.$ SKOV-3 Luc IP2 cells) miliary PM was observed with a tumor induction rate of $100 \%(3 / 3)$.

To assess whether it was possible to perform (e)PIPAC in tumor bearing rats, this procedure was performed with saline on day 28 in the athymic nude rats of group 3. All athymic nude rats survived this procedure. On day 29 , the rats of group 3 were sacrificed and autopsy was done. Diffuse PM with widespread small tumor nodules could be demonstrated (Fig. 5). Tumor nodules were embedded in paraffin before standard $H \& E$ staining was conducted. H\&E staining confirmed the presence of tumor cells in the nodules (Fig. 6).

\section{Discussion}

The prognosis of patients with irresectable PM is poor, with a median survival ranging from several weeks to months [3-5]. Recently, PIPAC has been introduced in clinical practice [21]. During PIPAC, chemotherapy is delivered as an aerosol, generated by a nebulizer (Capnopen $^{\circ}$ ) connected to a high-pressure injector. This novel approach may overcome two major limitations of conventional liquid based IP chemotherapy: incomplete coverage the peritoneal surfaces and poor tissue drug penetration [22, 23]. The increased intra-abdominal pressure during PIPAC by means of the capnoperitoneum may overcome the high interstitial fluid pressure in tumor tissue, and therefore improve tissue penetration [9]. Also, IP delivery of therapeutic agents as an aerosol result in a more homogeneous distribution compared to liquid instillation $[12,17,21]$. However, the 

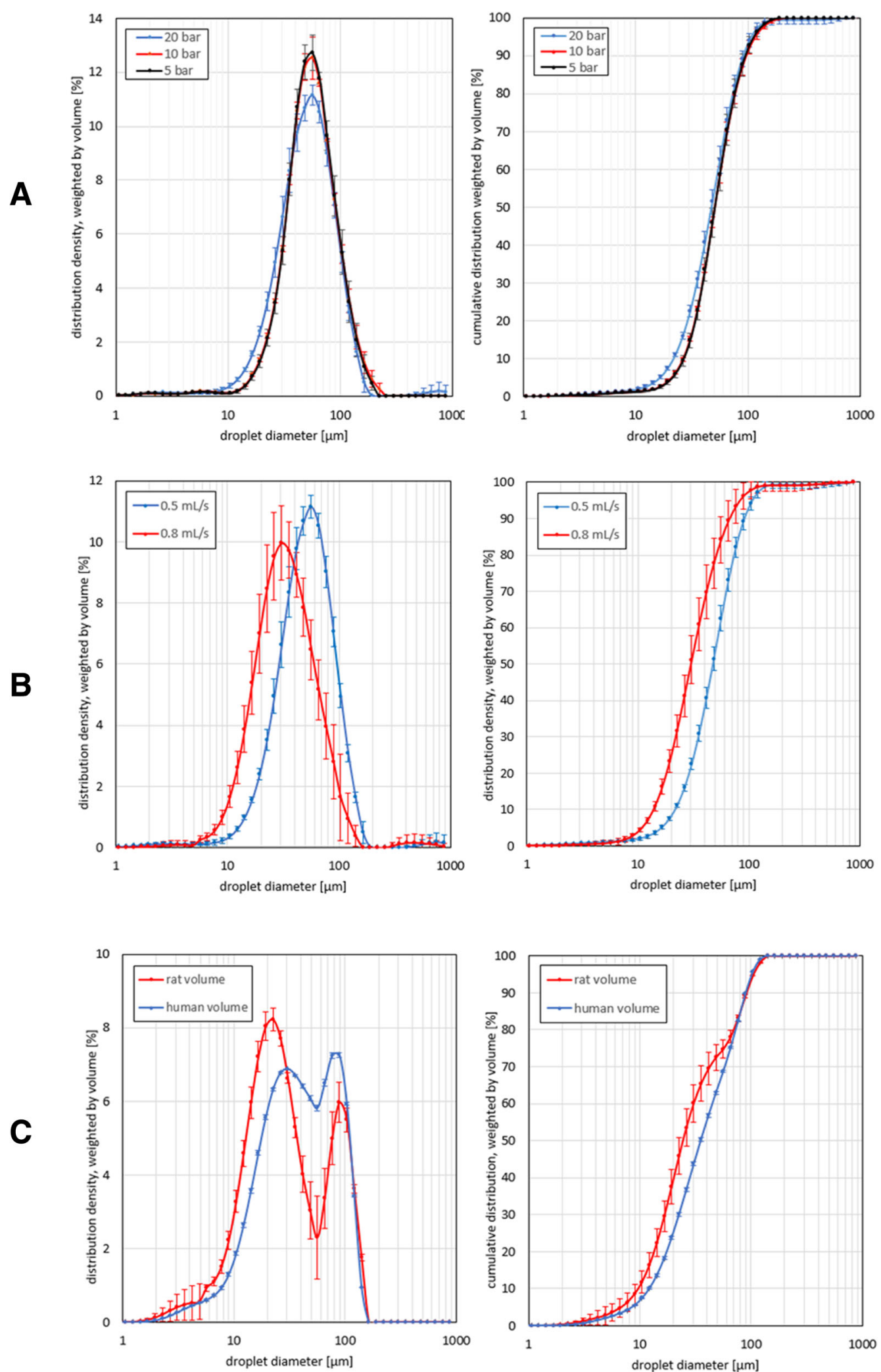

Fig. 2 (See legend on next page.) 
(See figure on previous page.)

Fig. 2 PSD curves of nebulized saline showing the distribution density (left curves) and cumulative distribution (right curves). Mean droplet diameters were measured ( $n=3$ for each confirmation) in a range of 0.5 to $900 \mu \mathrm{m}$. The error bars show one time the standard deviation. a Volume-weighted PSD curves showing the influence of maximal upstream injection pressure on $\mathrm{D}(\mathrm{v}, 0.5) .20 \mathrm{~mL}$ of saline was nebulized in open space at a fixed flow rate of $0.5 \mathrm{~mL} / \mathrm{s}$ and a maximal upstream injection pressure of 20 bar (blue graph), 10 bar (red graph) or 5 bar (black graph). b Volume-weighted PSD curves illustrating the influence of flow rate on $D(v, 0.5) .20 \mathrm{~mL}$ of saline was nebulized in open space at a fixed maximal upstream injection pressure of 20 bar and a flow rate of $0.5 \mathrm{~mL} / \mathrm{s}$ (blue graph) or $0.8 \mathrm{~mL} / \mathrm{s}$ (red graph). c Volume-weighted PSD curves demonstrating the influence of the volume of the peritoneal cavity on $\mathrm{D}(\mathrm{v}, 0.5)$. To simulate a nebulization in a rat's abdominal cavity, $20 \mathrm{~mL}$ of saline was nebulized in a plastic box $(V=100 \mathrm{~mL}$ ) with a flow rate of $0.8 \mathrm{~mL} / \mathrm{s}$ and a maximal upstream injection pressure of 20 bar (red graph). $200 \mathrm{~mL}$ of saline was nebulized in a plastic box $(\mathrm{V}=5 \mathrm{~L}$ ) with a flow rate of $0.5 \mathrm{~mL} / \mathrm{s}$ and a maximal upstream injection pressure of 20 bar (blue graph) as a comparison with the nebulization in human. The plastic boxes were bilaterally pierced to transvers laser light and a third perforation was made at the top of the boxes to insert the nebulizer

biophysical, pharmacokinetic, and anticancer properties and parameters that are relevant in PIPAC remain relatively unknown. To date, four models were reported for (e)PIPAC research: in vitro using cancer cells, an ex vivo box model, an ex vivo bovine urinary bladder model and an in vivo pig model [13-17, 24, 25]. We report a standardized rat model that allows to study biophysical, pharmacokinetic, and anticancer properties of PIPAC and electrostatic precipitation combined with PIPAC.

The first step was to ascertain that the model generates an aerosol that is comparable to the clinical situation. In clinical practice, the recommended settings are: nebulization of a volume of 150 to $200 \mathrm{~mL}$, maximal upstream injection pressure of $20 \mathrm{bar}$, flow rate of $0.5 \mathrm{~mL} / \mathrm{s}$ and a capnoperitoneum pressure of $12 \mathrm{mmHg}$ [21]. The resulting aerosol droplet size is reported to be in the range of $30-40 \mu \mathrm{m}$ [26]. In vitro granulometric analyses performed by Göhler et al. showed that the Capnopen ${ }^{\circ}$ generated aerosol consists of a bimodal volume-weighted PSD with a $\mathrm{D}(\mathrm{v}, 0.5)$ of $25 \mu \mathrm{m}$ [27]. The authors argue, based on theoretical assumptions and calculations, that the ideal droplet size to obtain a gas-like behaviour should be $1.2 \mu \mathrm{m}$ (for Stokes numbers of Stk =1) [27]. The droplet size of the aerosol is indeed important for its physical behaviour in the peritoneal cavity (diffusion versus sedimentation or inertial impaction), but may also affect tissue penetration of the administered cytotoxic agent [27, 28]. In pulmonary medicine, only very small $(<5 \mu \mathrm{m})$ particles reach the alveoles and exert a meaningful therapeutic effect. [29-31] It should be noted that smaller particles carry less drug mass, and that the anatomical restrictions that apply to the respiratory tree do not apply to the peritoneal cavity. For instance, large $(>10 \mu \mathrm{m})$ inhaled particles tend to be deposited in the larynx or upper airways, which is undesirable, but in PIPAC treatment size considerations seem to be less important. Nevertheless, the current and ideal PIPAC droplet size, and the biophysical parameters that affect it, should be further characterized. In our model, analysis of volume-weighted PSD curves demonstrated that $\mathrm{D}(\mathrm{v}, 0.5)$ is $47 \mu \mathrm{m}$ when a flow rate of $0.5 \mathrm{~mL} / \mathrm{s}$ and a maximal upstream injection pressure of $20 \mathrm{bar}$ are used (Fig. 2a). Increasing the flow rate to $0.8 \mathrm{~mL} / \mathrm{s}$ resulted in a statistically significant decrease of $\mathrm{D}(\mathrm{v}, 0.5)$ to $30 \mu \mathrm{m}$, an observation in accordance with experience from nozzles used in inlet fogging of gas turbine engines [32]. Interestingly, after nebulization of saline in a plastic box, a bimodal volume-weighted PSD distribution curves was observed, possibly explained by aggregation of the injected aerosol droplets.

Next, we studied homogeneity of aerosol distribution using a dye. It was observed that distribution of undiluted royal blue ink is improved when the nebulizer was held in a slightly tilted position; this could be

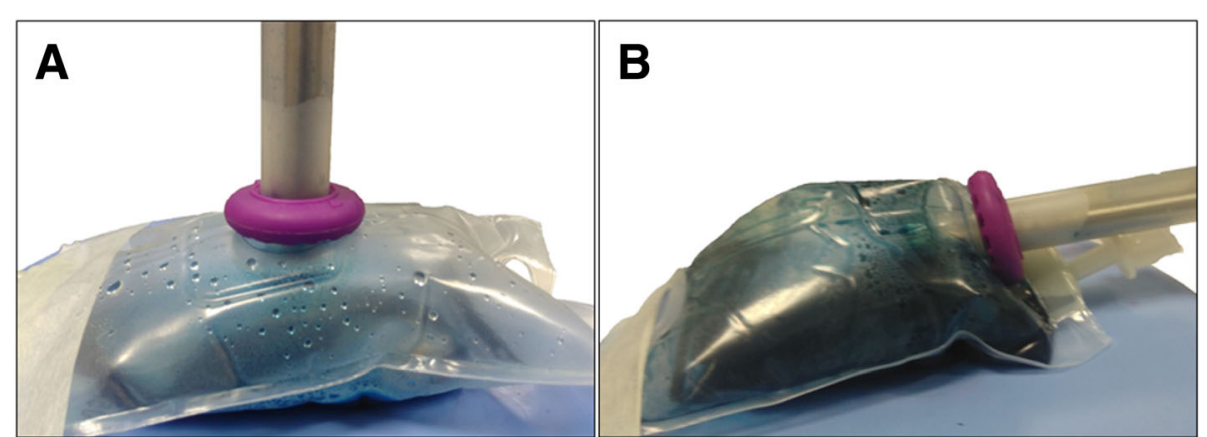

Fig. 3 Distribution pattern of $20 \mathrm{~mL}$ undiluted royal blue ink. The injection parameters were set on a flow rate of $0.8 \mathrm{~mL} / \mathrm{s}$, a maximal upstream injection pressure of 20 bar and an intracavitary pressure of $8 \mathrm{mmHg}$. a Blue ink distribution was limited to the bottom of the EVA bag when the nebulizer was perpendicularly secured. $\mathbf{b}$ Complete staining of the EVA bag was observed when the nebulizer was placed in a tilted position 


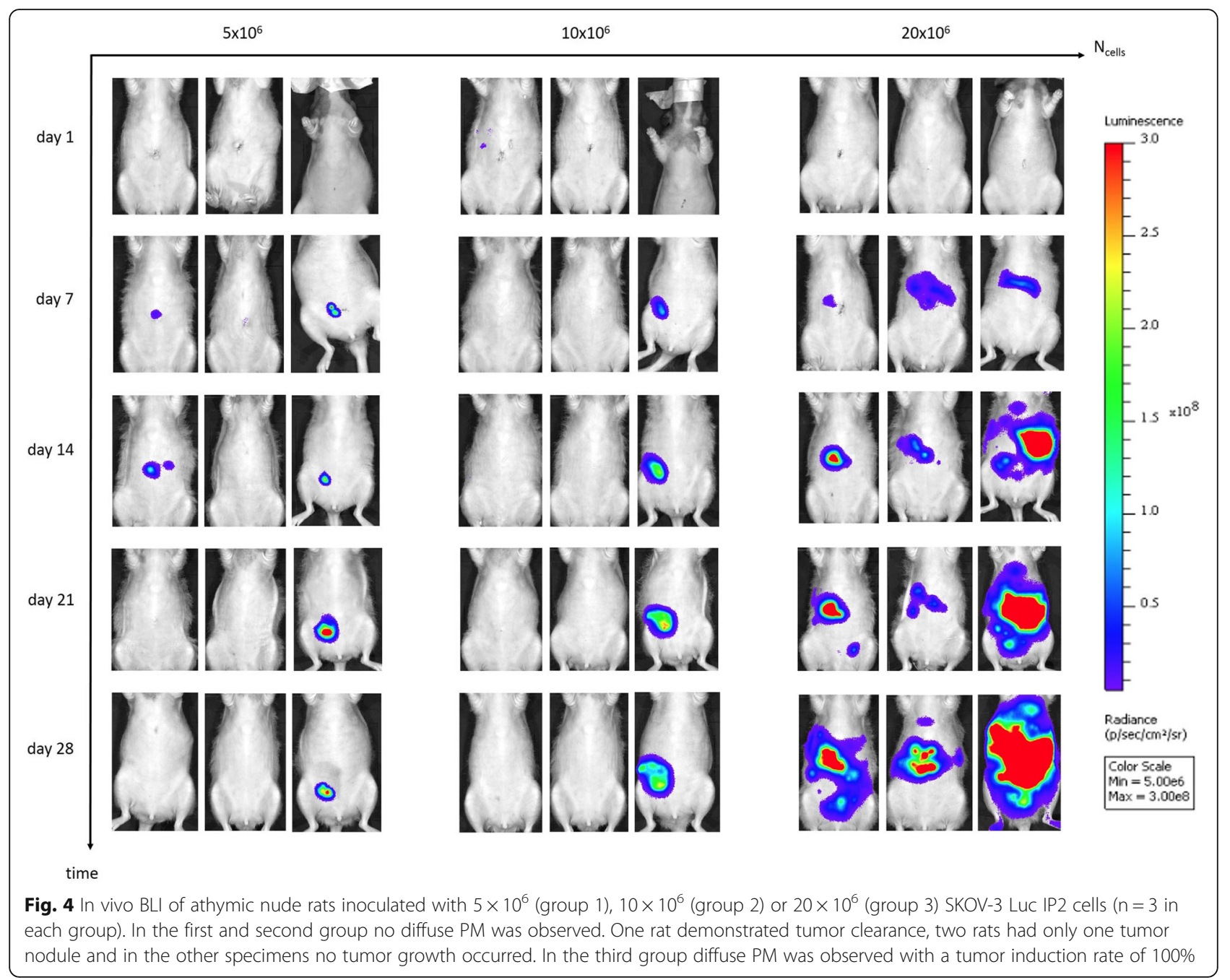

explained by a longer travelling distance of the injected aerosol droplets compared to the perpendicular position.

For the in vivo experiments, the pneumoperitoneum pressure was set at $8 \mathrm{~mm}$ of $\mathrm{Hg}$, since it is well known that an intra-abdominal pressure of $12 \mathrm{mmHg}$ is poorly tolerated in rats [33, 34]. Preliminary results showed excellent tolerance of both PIPAC and electrostatic precipitation. With experience, the total procedure time (from start to end of anesthesia) was $\pm 100 \mathrm{~min}$. The ovarian cancer xenograft model, resulting in widespread military PM, was successfully established after increasing the number of SKOV-3 Luc IP2 cells to $20 \times 10^{6}$ and with concurrent administration of cyclosporin. The required number of cells may appear high, but it is known that athymic rats have a lower degree of immune deficiency compared to athymic mice [35]. This model now offers the opportunity to study the anticancer effects of (e)PIPAC either alone or in combination with systemic treatment. Since immunotherapy offers considerable promise in ovarian cancer, the availability of a syngeneic OC model in immune competent animals would allow to study PIPAC in combination with immunotherapy. A syngeneic rat OC model, based on IP injection of NuTu-19 cells in female Fischer 344 rats, has been described [36], and may represent an interesting future addition to the xenograft model that we propose. Also, the use of immune competent animals allows to study how PIPAC treatment affects the peritoneal immune environment, a relevant parameter in the biology of post-therapy recurrence.

The major limitation of our model is related to the large difference in size between the rat and the human peritoneal cavity. This requires scaling of the effects found, and some clinical apparatus and methods may work differently when used in a rat. As an example, when using the clinically used electrostatic generator for ePIPAC in a rat, the shorter distance between electrode and grounding plate will result in a much stronger electrical field (volt/meter). In the future, we will study ePIPAC using a custom made apparatus that allows to vary voltage, current, and polarity. 

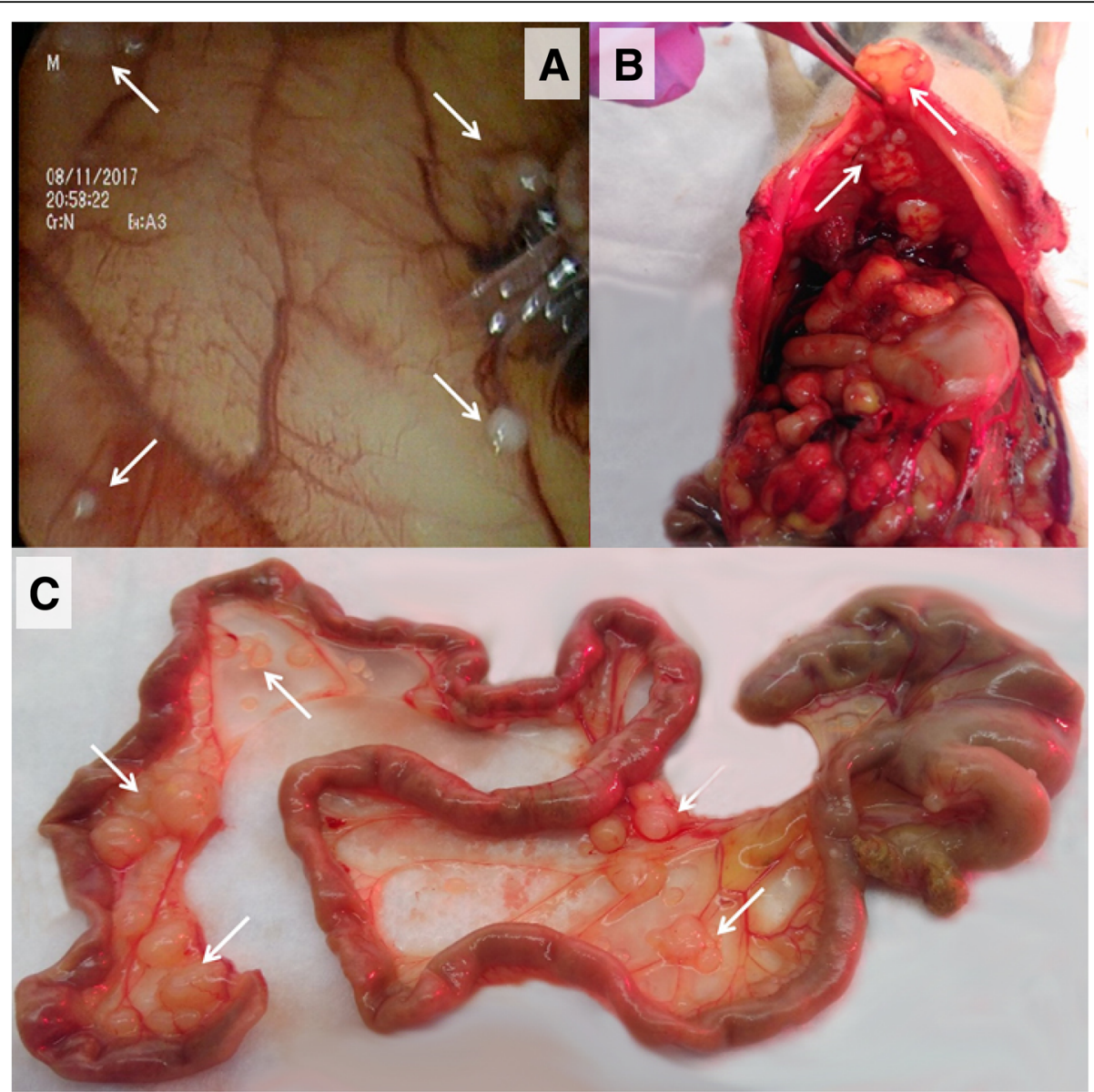

Fig. 5 Tumor nodules (white arrows) in athymic nude rats inoculated intraperitoneally with $20 \times 10^{6}$ SKOV-3 Luc IP2 cells. a Laparoscopic image of the right upper abdomen. $\mathbf{b}$ Post-mortem view of the upper abdomen. $\mathbf{c}$ Intestines and mesentery

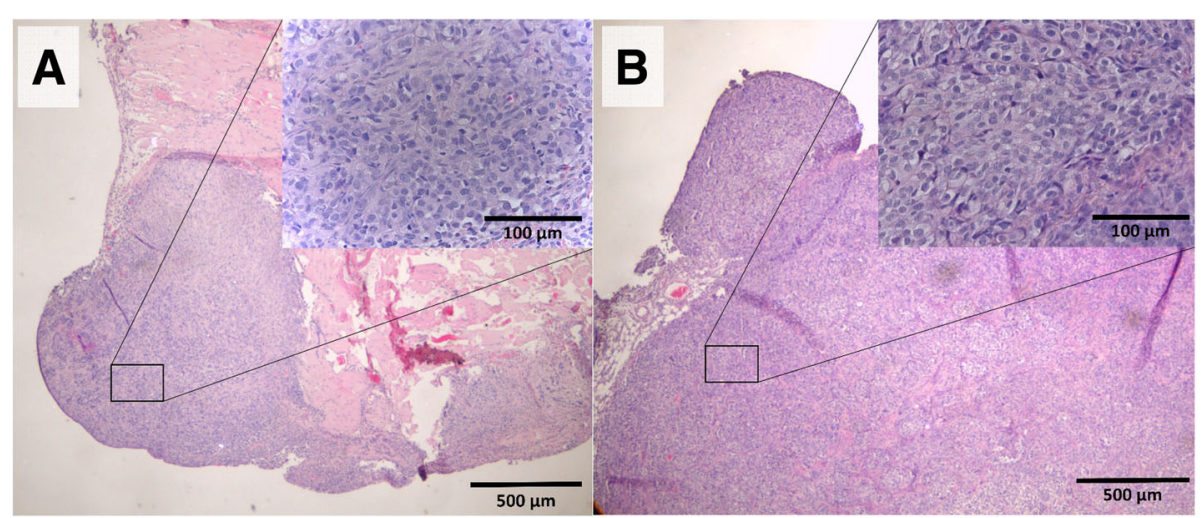

Fig. 6 H\&E stainings of peritoneal implants at the parietal peritoneum (a) and mesentery (b), 40x magnification. In the right upper corner, a close up of the H\&E staining is shown, 400x magnification. The typical morphology of cancer cells can be detected 


\section{Conclusion}

We report the first reproducible small animal model of PIPAC and ePIPAC in human ovarian PM bearing rats. This model will allow to study essential technology related aspects, pharmacokinetics and tissue penetration, and the activity of aerosolized anticancer therapies.

\section{Abbreviations}

BLI: Bioluminiscent imaging; CRS: Cytoreductive surgery; $D(v, 0.5)$ : Median of volume distribution; ePIPAC: Electrostatic aerosol precipitation with PIPAC; EVA: Ethylene vinyl acetate; H\&E: Hematoxylin and eosin; HIPEC: Hyperthermic intraperitoneal chemoperfusion; IP: Intraperitoneal; OC: Ovarian cancer; PIPAC: Pressurized intraperitoneal aerosol chemotherapy; PM: Peritoneal metastases; PSD: Particle size distribution; Stk: Stokes number

\section{Acknowledgements}

The authors thank their lab technician Evelien Dierick for conducting H\&E stainings. We also thank the staff of Infinity IBiTech-MEDISIP (Christian Van Hove and Benedicte Descamp) and Laboratory of Pharmaceutical Technology (Valérie Vanhoorne and Chris Vervaet) for providing their devices. MS is an ERS from the International Training Network 'Nanomed'. Wim Ceelen is a senior clinical investigator from the Fund for Scientific Research - Flanders (FWO)

\section{Funding}

No funding was received.

\section{Availability of data and materials}

The datasets used and/or analyses during the study available from the corresponding author on reasonable request.

\section{Authors' contributions}

LVDS designed the ex vivo and in vivo experiments, KDC designed the granulometric experiments. LVDS and KDC conducted the granulometric experiments. LVDS performed the ex vivo simulation of PIPAC. LVDS and WW made the (e)PIPAC rat model. LVDS and MS performed cell culturing. LVDS made the rat ovarian PM model. LVDS performed data analysis. LVDS, WW, SC, KR and WC discussed the results. LVDS has drafted the manuscript and WW, SC, KR, WC substantively revised it. All authors read and approved the final manuscript.

\section{Ethics approva}

The study protocol was approved by the Animal Ethical Committee of the Faculty of Medicine, Ghent University, Belgium (ECD 17-50 and ECD 18-30). The human cell lines did not require ethics approval from our institution as they were purchased from legal commercial product.

\section{Consent for publication}

Not applicable.

\section{Competing interests}

The authors declare that they have no competing interests.

\section{Publisher's Note}

Springer Nature remains neutral with regard to jurisdictional claims in published maps and institutional affiliations.

\section{Author details}

${ }^{1}$ Laboratory of Experimental Surgery, Department of Human Structure and Repair, Ghent University, Ghent, Belgium. ${ }^{2}$ Cancer Research Institute Ghent (CRIG), Ghent University, Ghent, Belgium. '²aboratory of Pharmaceutical Technology, Department of Pharmaceutics, Ghent University, Ghent, Belgium. ${ }^{4}$ Laboratory for General Biochemistry and Physical Pharmacy, Department of Pharmaceutics, Ghent University, Ghent, Belgium. '5epartment of GI Surgery, Ghent University Hospital, route 1275, C. Heymanslaan 10, B-9000 Ghent, Belgium.
Received: 5 December 2018 Accepted: 30 April 2019

Published online: 07 May 2019

\section{References}

1. Al Rawahi T, Lopes AD, Bristow RE, Bryant A, Elattar A, Chattopadhyay S Galaal K. Surgical cytoreduction for recurrent epithelial ovarian cancer. Cochrane Database Syst Rev. 2013;(2):CD008765. https://doi.org/10.1002/14651858.CD008765.pub3.

2. Oseledchyk A, Zivanovic O. Intraoperative Hyperthermic intraperitoneal chemotherapy in patients with advanced ovarian Cancer. Oncology (Williston Park, NY). 2015;29:695-701.

3. Klaver YLB, Simkens LHJ, Lemmens VEPP, Koopman M, Teerenstra S, Bleichrodt RP, de Hingh IHJT, Punt CJA. Outcomes of colorectal cancer patients with peritoneal carcinomatosis treated with chemotherapy with and without targeted therapy. Eur J Surg Oncol. 2012;38:617-23. https://doi.org/10.1016/j.ejso.2012.03.008.

4. Thomassen I, van Gestel YR, van Ramshorst B, Luyer MD, Bosscha K, Nienhuijs SW, Lemmens VE, de Hingh $1 \mathrm{H}$. Peritoneal carcinomatosis of gastric origin: a population-based study on incidence, survival and risk factors. Int J Cancer. 2014;134:622-8. https://doi.org/10.1002/ijc.28373.

5. Thomassen I, Lemmens VEPP, Nienhuijs SW, Luyer MD, Klaver YL, de Hingh IHJT. Incidence, prognosis, and possible treatment strategies of peritoneal carcinomatosis of pancreatic origin: a population-based study. Pancreas. 2013:42:72-5. https://doi.org/10.1097/MPA.0b013e31825abf8c.

6. Winner KK, Steinkamp MP, Lee RJ, Swat M, Muller CY, Moses ME, Jiang Y, Wilson BS. Spatial modeling of drug delivery routes for treatment of disseminated ovarian cancer. Cancer Res. 2016;76:1320-34. https://doi.org/ 10.1158/0008-5472.CAN-15-1620.

7. Tempfer CB. Pressurized intraperitoneal aerosol chemotherapy as an innovative approach to treat peritoneal carcinomatosis. Med Hypotheses. 2015:85:480-4. https://doi.org/10.1016/j.mehy.2015.07.001.

8. Grass F, Vuagniaux A, Teixeira-Farinha H, Lehmann K, Demartines N, Hübner M. Systematic review of pressurized intraperitoneal aerosol chemotherapy for the treatment of advanced peritoneal carcinomatosis. Br J Surg. 2017; 104:669-78. https://doi.org/10.1002/bjs.10521.

9. Esquis $P$, Consolo D, Magnin G, Pointaire P, Moretto P, Ynsa MD, Beltramo JL, Drogoul C, Simonet M, Benoit L, Rat P, Chauffert B. High intra-abdominal pressure enhances the penetration and antitumor effect of intraperitoneal cisplatin on experimental peritoneal carcinomatosis. Ann Surg. 2006;244: 106-12. https://doi.org/10.1097/01.sla.0000218089.61635.5f.

10. Reymond M, Demtroeder C, Solass W, Winnekendonk G, Tempfer C. Electrostatic precipitation pressurized IntraPeritoneal aerosol chemotherapy (ePIPAC): first in-human application. Pleura and Peritoneum. 2016;1:109-16. https://doi.org/10.1515/pp-2016-0005.

11. Ansell J, Warren N, Wall P, Cocks K, Goddard S, Whiston R, Stechman M, Scott-Coombes D, Torkington J. Electrostatic precipitation is a novel way of maintaining visual field clarity during laparoscopic surgery: a prospective double-blind randomized controlled pilot study. Surg Endosc. 2014;28:205765. https://doi.org/10.1007/s00464-014-3427-8.

12. Kakchekeeva T, Demtröder C, Herath NI, Griffiths D, Torkington J, Solaß W, Dutreix M, Reymond MA. In vivo feasibility of electrostatic precipitation as an adjunct to pressurized intraperitoneal aerosol chemotherapy (ePIPAC). Ann Surg Oncol. 2016;23:592-8. https://doi.org/10.1245/s10434-016-5108-4.

13. Khosrawipour V, Diaz-Carballo D, Ali-Haydar A, Khosrawipour T, Falkenstein TA, Wu D, Zieren J, Giger-Pabst U. Cytotoxic effect of different treatment parameters in pressurized intraperitoneal aerosol chemotherapy (PIPAC) on the in vitro proliferation of human colonic cancer cells. World J Surg Oncol. 2017;15:43. https://doi.org/10.1186/s12957-017-1109-4.

14. Solass W, Herbette A, Schwarz T, Hetzel A, Sun J-S, Dutreix M, Reymond MA Therapeutic approach of human peritoneal carcinomatosis with Dbait in combination with capnoperitoneum: proof of concept. Surg Endosc. 2012; 26:847-52. https://doi.org/10.1007/s00464-011-1964-y.

15. Khosrawipour V, Khosrawipour T, Falkenstein TA, Diaz-Carballo D, Foerster E, Osma A, Adamietz IA, Zieren J, Fakhrian K. Evaluating the effect of micropump (c) position, internal pressure and doxorubicin dosage on efficacy of pressurized intra-peritoneal aerosol chemotherapy (PIPAC) in an ex vivo model. Anticancer Res. 2016;36:4595-600. https://doi.org/10.21873/anticanres.11008.

16. Schnelle D, Weinreich F-J, Kibat J, Reymond MA. A new ex vivo model for optimizing distribution of therapeutic aerosols: the (inverted) bovine urinary bladder. Pleura and Peritoneum. 2017:2·37-41. https://doi.org/10.1515/pp-2017-0006. 
17. Solaß W, Hetzel A, Nadiradze G, Sagynaliev E, Reymond MA. Description of a novel approach for intraperitoneal drug delivery and the related device. Surg Endosc. 2012;26:1849-55. https://doi.org/10.1007/s00464-012-2148-0.

18. Alyami M, Gagniere J, Sgarbura O, Cabelquenne D, Villeneuve L, Pezet D, Quenet F, Glehen O, Bakrin N, Passot G. Multicentric initial experience with the use of the pressurized intraperitoneal aerosol chemotherapy (PIPAC) in the management of unresectable peritoneal carcinomatosis. EJSO. 2017;43: 2178-83. https://doi.org/10.1016/j.jso.2017.09.010.

19. Nowacki M, Alyami M, Villeneuve L, Mercier F, Hubner M, Willaert W, Ceelen W, Reymond M, Pezet D, Arvieux C, Khomyakov V, Lay L, Gianni S, Zegarski W, Bakrin N, Glehen O. Multicenter comprehensive methodological and technical analysis of 832 pressurized intraperitoneal aerosol chemotherapy (PIPAC) interventions performed in 349 patients for peritoneal carcinomatosis treatment: an international survey study. EJSO. 2018:44:9916. https://doi.org/10.1016/j.jso.2018.02.014.

20. De Vlieghere E, Carlier C, Ceelen W, Bracke M, De Wever O. Data on in vivo selection of SK-OV-3 Luc ovarian cancer cells and intraperitoneal tumor formation with low inoculation numbers. Data Brief. 2016;6:542-9. https://doi.org/10.1016/j.dib.2015.12.037.

21. Solass W, Kerb R, Mürdter T, Giger-Pabst U, Strumberg D, Tempfer C, Zieren J, Schwab M, Reymond MA. Intraperitoneal chemotherapy of peritoneal Carcinomatosis using pressurized aerosol as an alternative to liquid solution: first evidence for efficacy. Ann Surg Oncol. 2014;21:553-9. https://doi.org/10.1245/s10434-013-3213-1.

22. Dedrick RL, Flessner MF. Pharmacokinetic problems in peritoneal drug administration: tissue penetration and surface exposure. J Natl Cancer Inst. 1997;89:480-7. https://doi.org/10.1093/jnci/89.7.480.

23. Tempfer CB, Hilal Z, Dogan A, Petersen M, Rezniczek GA. Concentrations of cisplatin and doxorubicin in ascites and peritoneal tumor nodules before and after pressurized intraperitoneal aerosol chemotherapy (PIPAC) in patients with peritoneal metastasis. Eur J Surg Oncol. 2018;44:1112-7. https://doi.org/10.1016/j.ejso.2018.04.020.

24. Khosrawipour V, Khosrawipour T, Kern AJP, Osma A, Kabakci B, Diaz-Carballo D, Förster E, Zieren J, Fakhrian K. Distribution pattern and penetration depth of doxorubicin after pressurized intraperitoneal aerosol chemotherapy (PIPAC) in a postmortem swine model. J Cancer Res Clin Oncol. 2016;142: 2275-80. https://doi.org/10.1007/s00432-016-2234-0.

25. Tempfer C, Giger-Pabst U, Hilal Z, Dogan A, Rezniczek GA. Pressurized intraperitoneal aerosol chemotherapy (PIPAC) for peritoneal carcinomatosis: systematic review of clinical and experimental evidence with special emphasis on ovarian cancer. Arch Gynecol Obstet. 2018;298:234-57. https://doi.org/10.1007/s00404-018-4784-7.

26. Reymond MA, Solass W. PIPAC: pressurized IntraPeritoneal aerosol chemotherapy - Cancer under pressure. Berlin: Walter de Gruyter GmbH \& Co KG; 2014.

27. Göhler D, Khosrawipour V, Khosrawipour T, Diaz-Carballo D, Falkenstein TA, Zieren J, Stintz M, Giger-Pabst U. Technical description of the microinjection pump (MIP®) and granulometric characterization of the aerosol applied for pressurized intraperitoneal aerosol chemotherapy (PIPAC). Surg Endosc. 2016:1-7. https://doi.org/10.1007/s00464-016-5174-5.

28. Try C, Moulari B, Béduneau A, Fantini O, Pin D, Pellequer $Y$, Lamprecht $A$. Size dependent skin penetration of nanoparticles in murine and porcine dermatitis models. Eur J Pharm Biopharm. 2016;100:101-8. https://doi.org/10.1016/j.ejpb.2016.01.002.

29. Dalby RN, Eicher J, Zierenberg B. Development of Respimat ${ }^{\oplus}$ soft mist ${ }^{\text {TM }}$ inhaler and its clinical utility in respiratory disorders. Med Devices (Auckl). 2011;4:145-55. https://doi.org/10.2147/MDER.S7409.

30. Labiris NR, Dolovich MB. Pulmonary drug delivery. Part I: physiological factors affecting therapeutic effectiveness of aerosolized medications. Br J Clin Pharmacol. 2003;56:588-99. https://doi.org/10.1046/j.1365-2125.2003.01892.x.

31. Carvalho TC, Peters JI, Williams RO. Influence of particle size on regional lung deposition - what evidence is there? Int J Pharm. 2011;406:1-10. https://doi.org/10.1016/j.jpharm.2010.12.040

32. Chaker MA. Key Parameters for the Performance of Impaction-Pin Nozzles Used in Inlet Fogging of Gas Turbine Engines 2005;4:91-97. doi:https://doi.org/10.1115/GT2005-68346.

33. Niu X, Song X, Su A, Zhao S, Li Q. Low-pressure capnoperitoneum reduces stress responses during pediatric laparoscopic high ligation of indirect inquinal hernia sac. Medicine (Baltimore). 2017:96:e6563. https://doi.org/10.1097/MD.0000000000006563.
34. Schmandra TC, Kim ZG, Gutt CN. Effect of insufflation gas and intraabdominal pressure on portal venous flow during pneumoperitoneum in the rat. Surg Endosc. 2001;15:405-8. https://doi.org/10.1007/s004640000331.

35. Mashimo T, Takizawa A, Kobayashi J, Kunihiro Y, Yoshimi K, Ishida S, Tanabe K, Yanagi A, Tachibana A, Hirose J, Yomoda J, Morimoto S, Kuramoto T, Voigt B, Watanabe T, Hiai H, Tateno C, Komatsu K, Serikawa T. Generation and characterization of severe combined immunodeficiency rats. Cell Rep. 2012;2:685-94. https://doi.org/10.1016/j.celrep.2012.08.009.

36. Azaïs H, Queniat G, Bonner C, Kerdraon O, Tardivel M, Jetpisbayeva G, Frochot C, Betrouni N, Collinet P, Mordon S. Fischer 344 Rat: a preclinical model for epithelial ovarian Cancer folate-targeted therapy. Int J Gynecol Cancer. 2015;25:1194-200. https://doi.org/10.1097/IGC.0000000000000497.

\section{Ready to submit your research? Choose BMC and benefit from:}

- fast, convenient online submission

- thorough peer review by experienced researchers in your field

- rapid publication on acceptance

- support for research data, including large and complex data types

- gold Open Access which fosters wider collaboration and increased citations

- maximum visibility for your research: over $100 \mathrm{M}$ website views per year

At $\mathrm{BMC}$, research is always in progress.

Learn more biomedcentral.com/submissions 